\title{
Rechtspluralismus in der Islamischen Welt. Gewohnheitsrecht zwischen Staat und Gesellschaft. Berlin-New York, Walter de Gruyter, 2005, 378 p.
}

\section{Alexandre Papas}

\section{(2) OpenEdition}

1 Journals

\section{Édition électronique}

URL : http://journals.openedition.org/abstractairanica/9152

DOI : 10.4000/abstractairanica.9152

ISSN : 1961-960X

Éditeur :

CNRS (UMR 7528 Mondes iraniens et indiens), Éditions de l'IFRI

\section{Édition imprimée}

Date de publication : 15 mai 2007

ISSN : 0240-8910

\section{Référence électronique}

Alexandre Papas, «Rechtspluralismus in der Islamischen Welt. Gewohnheitsrecht zwischen Staat und Gesellschaft. Berlin-New York, Walter de Gruyter, 2005, 378 p. », Abstracta Iranica [En ligne], Volume 28 | 2007, document 11, mis en ligne le 18 septembre 2007, consulté le 25 septembre 2020. URL http://journals.openedition.org/abstractairanica/9152 ; DOI : https://doi.org/10.4000/ abstractairanica. 9152

Ce document a été généré automatiquement le 25 septembre 2020.

Tous droits réservés 


\title{
Rechtspluralismus in der Islamischen Welt. Gewohnheitsrecht zwischen Staat und Gesellschaft. Berlin-New York, Walter de Gruyter, 2005, 378 p.
}

\author{
Alexandre Papas
}

1 Sujet fondamental mais encore peu traité, le droit coutumier en islam ('ādat dans la terminologie musulmane), comme le précisent les éditeurs dès leur introduction au volume, est ici étudié dans la multiplicité des situations historiques et géographiques, et sous le regard de disciplines diverses. À travers ces différentes études de cas, c'est essentiellement le problème du rapport au pouvoir politique qui se profile, selon quatre types distincts: la fondation d'un État musulman sur le droit coutumier local ou régional; l'incorporation par l'État dans son système juridique du 'ādat issu de communautés allogènes ; la possibilité pour un État de faire autorité, en son droit, par différents moyens ; le cas d'une conquête étrangère et de l'introduction de son propre droit coutumier dans la société musulmane. Dans cette perspective, le facteur colonial (français et surtout russe) est largement évoqué et analysé avec précision dans ses conséquences juridiques et sociales. Le livre contient les articles suivants :

Ch. Müller, "Sitte, Brauch und Gewohnheitsrecht im mālikitischen figh »; R. Elger, " 'Urf and šarīa im Südmarokko des 19. Jahrhunderts: Al-MuHtāàr as-Sūsīs Biographiensammlung al-Matsūl als Quelle »; T. Hannemann, "Gewohnheitsrechte in einer islamischen Rechtsumgebung: Theoretische Vergleichsperspektiven aus der Großen Kabylei »; Ch. Rauch, «Die jemenitischen hiğras zwischen Stamm and Staat »; F. \& K. von Benda-Beckmann, "Adat, Islam und Staat - Rechtspluralismus in Indonesien»; K. Kaser, "Gewohnheitsrecht und Geschlechterbeziehungen im osmanischen Europa »; M. Reinkowski, «Gewohnheitsrecht im multinationalen Staat: Die Osmanen und der albanische Kanun »; B.G. Fragner, « Mongolisches Erbe unter den 
Strenggläubigen: Die Karriere des unislamischen Gewohnheitsrecht in den nachmittelalterlichen Staaten im iranischen Hochland»; Ch. Werner, " Urf oder Gewohnheitsrecht in Iran: Quellen, Praxis and Begrifflichkeit »; Ch. Nölle-Karimi, « Die paschtunische Stammesversammlung im Spiegel der Geschichte »; S. A. Abašin, « Qalïm and mahr in Mittelasien: Die moderne Praxis und die Debatten über Scharia und Adat »; I. Bellér-Hann, «Gewohnheitsrecht unter den Uighuren im ländlichen Xinjiang »; O. I. Brusina, «Die Transformation des Adat-Gerichte bei den Nomaden Turkestans in der zweiten Hälfte des 19. Jahrhunderts »; I. L. Babič, «Die Rolle des Gewohnheitsrecht in der russischen Politik in nordwestlichen und zentralen Kaukasus: Geschichte und Gegenwart»; T. M. Aytberov, "Rechtsdokumente der awarisch-tschetschenischen Fürsten aus dem Daghestan des 17. Jahrhunderts »; « Übereinkünfte daghestanischer Dorfgemeinden: Die 'Ādāt von Hidatl» (Übersetzung von M. Kemper unter Mitarbeit von Daria Stepanova); V.O. Bobrovnikov, "Verbrechen und Brauchtum zwischen islamischen und imperialem Recht: Zur Entzauberung des iškīl im Daghestan des 17. bis 19. Jahrhunderts »; M. Kemper, "Arabischsprachige Adat-Ethnographie auf russische Bestellung? »; Z. ž. Kenžaliev, « Das kasachische Gewohnheitsrecht in sowjetischer und postsowjetischer Zeit »; J. Beyer, « Die Aksakal-Gerichte in Kirgistan: Entwicklung und aktuelle Situation einer traditionellen Rechtsinstitution ».

INDEX

Thèmes : 1.2. Recueils d'articles : revues, colloques, ouvrages collectifs

\section{AUTEURS}

ALEXANDRE PAPAS

EHESS - Paris 